\title{
Early Weaning Risk Factors for Acute Respiratory Infections
}

\author{
Eni Folendra Rosa, Gunardi Pome, D. Harsanto
}

Nursing Department of Baturaja, Polytechnic of Health Palembang, Indonesia

\begin{tabular}{l} 
Article Info \\
\hline Article history: \\
Received Apr 3, 2017 \\
Revised May 27, 2017 \\
Accepted Jun 9, 2017 \\
\hline
\end{tabular}

Keyword:

Early Weaning

Acute Respiratory Infections

Children Ages 6 to 24 Months

\begin{abstract}
Acute respiratory infections (ARIs) still a health problem in the world resulting in high mortality and morbidity. Every year 13 million children under five died, $95 \%$ of deaths occur in developing countries and 4.5 million deaths due to respiratory infection. Takes effort and hard work to reduce mortality of children under five are caused by ARIs. ARIs episodes in children under five in the world generally between 3-8 times every year. Breast milk is a natural nutrient that contain $\operatorname{IgA}(\mathrm{S} \operatorname{IgA}), \operatorname{IgE}, \operatorname{IgM}, \operatorname{IgG}$, lactoferin, lysozyme, vitamin A, C and E. SIgA generated broncho mammary and $\alpha 2$--microglobulin substances that protect against syncytial virus and inhibit and lowering the risk of infection with Haemophilus influenzae contained in the mouth and nose. Babies who are not breastfed full or partial ARIs at greater risk due to lack of intake of protective substances in the breast milk. The incidence of acute respiratory diseases are at highest order resulting morbidity and mortality of children in the district OKU in 2014 amounted to $52.2 \%$ and increased by $53 \%$ in 2015 . Unmatched case control study with a quantitative approach, the study subjects children aged 6-24 months. Data analysis using Stata program consists of univariable, bivariable and multivariable logistic regression with $95 \%$ CI. Significant relationship with ARIs early weaning ( $\mathrm{OR}=2.72 ; 95 \% \mathrm{CI}=1.08-6.83)$. The average episode of ARIs was 2.8 times every year. Early weaning increase risk of ARIs in children 6-24 months.
\end{abstract}

Copyright $(2017$ Institute of Advanced Engineering and Science. All rights reserved.

\section{Corresponding Author:}

Eni Folendra Rosa,

Nursing Department of Baturaja,

Polytechnic of Health Palembang.

Jl. Imam Bonjol No. 652 Baturaja 32112, South Sumatera, Indonesia

Email: enifrosa@gmail.com

\section{INTRODUCTION}

Acute respiratory infections ARIs called the forgotten pandemic, consists of pneumonia, bronchitis, bronchiolitis, otitis media, sinusitis, pharyngitis, measles and pertussis, and is still a major health problem because $19 \%$ of the causes of death and illness in the world. Every year there are 13 million children under five died, $95 \%$ of under five deaths occur in developing countries and one third due to respiratory infection [1]-[4]. Episodes of ARIs in infants differ generally occurs 3-6 times a year depending on the seriousness of the disease, in developed countries and developing countries are different than the etiology and risk factors were also influenced by demographic and sociocultural [1]. Case fatality rate of ARIs in infants is higher in developing countries compared to developed countries [5]. Overall incidence of ARIs in the developed and developing countries is almost equal to the average episodes in children 4-8 times every year, whereas in Indonesia episode ISPA is 3-6 times every year.

Mother's milk is a natural drink for newborns in the first month of life [6]. Babies who are not breastfed or breastfed partially filled with susceptible to respiratory diseases and diarrhea [1],[7]. Risk infants who are not breastfed get a full or partial breastfeeding on the incidence of death from respiratory diseases 3.27 times greater than with exclusive breastfeeding while other researchers reported the risk of 2.23 times 
higher for ARIs diarrhea occur. Breastfeeding for six months, and continue until one year could reduce the prevalence and morbidity caused by ARIs and other infections in infants [8]. WHO and UNICEF recommend exclusive breastfeeding at birth and remain fed along feeding mother's milk up to two years or more. Most mothers in various countries began to give food and beverage additives prior to 6 months, and stopped breastfeeding before the child is two years old, a common reason is the mother felt he did not have enough milk, mothers work outside the home and do not know how to breastfeed while working [9].

The survey results in Japan in 2005 showed a decrease pattern of breastfeeding infants, $46.4 \%$ at the age after one month, 38\% after age 3 months, and 6 months of age up by $34.7 \%$. Australia's breastfeeding behavior is relatively high ranging between $80-90 \%$, but it decreased $50-60 \%$ after infants aged 3 months, and $47 \%$ after 6 months of age [10]. Behavior breastfeeding infants are depending on ethnicity, socioeconomic and demographic factors. Mother's behavior did weaning age of 1 month amounted to $11.3 \%$, weaning age of 2 months at $18.1 \%$, the age of 3 months amounted to $25.4 \%$, age 4 months amounted to $30.7 \%$, age 5 months amounted to $34.9 \%$, and the age of 6 months at $40.8 \%$ [11].

Early weaning is a critical nutritional stage in a baby's life and optimal age to have been much debated. The decision when to weaning should be considered with the risk that a premature weaning would interfere with the digestive system, kidneys and immune system that can lead to immaturitas and reduced exposure to the protective effect of breastfeeding [12]. Early weaning is permanently discontinue breast feeding and not breastfeeding again to the newborn, and or cessation of breastfeeding from mothers to their babies before the age of 3 months [13],[14].

Bioactive components in breast milk protects babies against respiratory infections, such as spending immunoglobulin (SIgA) against syncytial virus produced from the bronchomammary and microglobulin $\alpha 2$ substance that inhibits influenza virus and parainfluensa. This supports the evidence that respiratory infections in infants who received breast milk in full, lighter than babies who received formula milk [15].

Patterns of breastfeeding in infants is associated with several things including maternal employment conditions, support from family, mother's knowledge, and providing access to health care facilities [16]. Another factor influencing the high incidence of ARIs in infants is also influenced by intrinsic factors such as age, sex, nutritional status, immunization status and birth weight and extrinsic factors such as housing, socialeconomic and educational [13]. Nutritional status affects the incidence of ARI in infants, infants with malnutrition and poor nutrition ISPA attacks become more frequent than the good nutrition. Toddler with malnutrition and undernourishment their immune systems are not working properly [17]. Malnutrition, low immunization coverage and the young age is a significant factor for the occurrence of pneumonia. OKU district showed that ARI always ranked top every year. The prevalence of ARIs in Toddlers 52\% (2014) and in 2015 with ARIs increased by 53\% [18]. Theoretical framework can be seen in Figure 1.

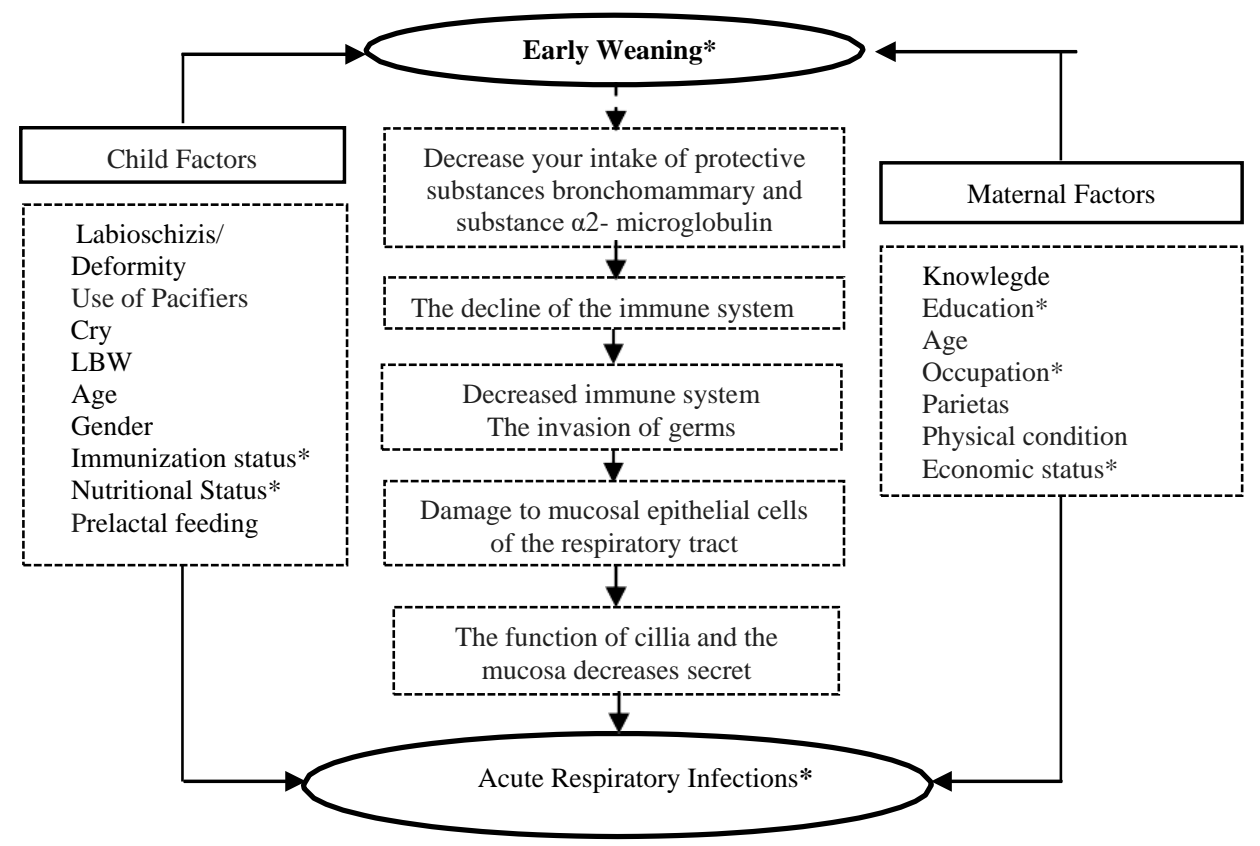

Figure 1. The theoretical framework of risk of early weaning on the incidence ARIs, modification theory [1],[15],[19],[2],[3],[13] 


\section{RESEARCH METHOD}

The observational studies unmatched case control study with a quantitative approach, the location of the research conducted in Ogan Komering Ulu district South Sumatera Indonesia from Maret 2016 to July 2016. Selection of research subjects with probability sampling, sample distribution is probability proportionate to size for the expected sample representative of the entire study site. The sample size was calculated using a software sample size is 192 respondents. Comparison sample case and control groups were 1:1, sample each group is 96 in the case group and the control group of 96 samples. Samples were selected if they meet the inclusion criteria is the age of the child at least 6 months and maximum 24 months in April 2016, agreed to participate in the study, respondents were mothers residing in the research sites, whereas the exclusion criteria is a child with a history of bronchial asthma and or pulmonary tuberculosis, a history of allergic disease and malnutrition. Ethical approval for the study was obtained from the Polytecnic of health of Palembang ethical review committee. The statistical software Stata was used for statistical analysis.

\section{RESULTS AND ANALYSIS}

\subsection{Analysis univariable}

In univariable demonstrated in the case group are subjected to early weaning, $77 \%, 58 \%$ complete immunization status, nutrition either $67 \%, 75 \%$ of mothers do not work, mothers education high school $\geq$ $87.5 \%$ and $62.5 \%$ of high economic status, whereas in the control group experienced early weaning as much as $53 \%$, mostly $83 \%$ complete immunization status, nutritional status of either $89.6 \%, 66.7 \%$ mothers do not work, higher education $87.5 \%$ and $83 \%$ of high economic status. Episode acute respiratory infections in Ogan Komering Ulu District South Sumatera Indonesia can be seen in Figure 2.

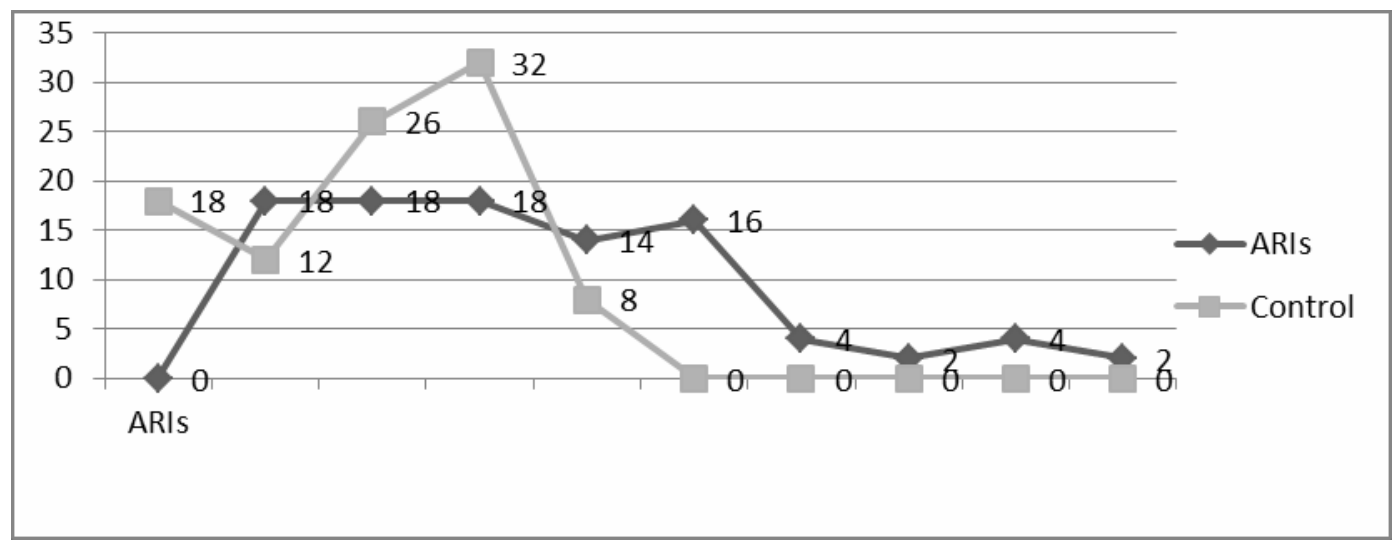

Figure 2. Episode acute respiratory infections in OKU District, South Sumatera, Indonesia

\subsection{Analysis Bivariate}

Table 1 shows that early weaning is a significant relationship to the ARIs $(p=0.01)$ in early weaning and can be summed risk 3.09 times greater in children than no ARIs group. In the analysis of the nutritional status obtained a significant correlation with the incidence of ARIs nutritional status $(\mathrm{p}=0.006)$, and it can be concluded under nutrition risk 4.3 times greater in the group of ARI compared to the control group. 
Table 1 . The Result of early weaning relationship analysis with incidence ARIs

\begin{tabular}{|c|c|c|c|c|c|}
\hline \multirow{2}{*}{ Variables } & \multicolumn{2}{|c|}{ The incidence of ARIs } & \multirow{2}{*}{$\mathrm{p}$ Value } & \multirow{2}{*}{ OR } & \multirow{2}{*}{ CI $95 \%$} \\
\hline & ARIs & No & & & \\
\hline \multicolumn{6}{|l|}{ Early Weaning } \\
\hline Yes & $74(77 \%)$ & $50(52 \%)$ & 0.01 & 3.09 & $1.18-8.28$ \\
\hline No & $22(23 \%)$ & $46(48 \%)$ & & & \\
\hline \multicolumn{6}{|l|}{ Nutrition Status } \\
\hline Poor & $32(33 \%)$ & $10(10 \%)$ & 0.006 & 4.3 & $1.30-16.36$ \\
\hline Good & $64(67 \%)$ & $86(90 \%)$ & & & \\
\hline \multicolumn{6}{|c|}{ Immunization status } \\
\hline Incomplete & $40(42 \%)$ & $16(17 \%)$ & 0.007 & 3.57 & $1.26-10.64$ \\
\hline Complete & $56(58 \%)$ & $80(83 \%)$ & & & \\
\hline \multicolumn{6}{|l|}{ Education } \\
\hline Low & $12(12.5 \%)$ & $12(12.5 \%)$ & 1.000 & 1.00 & $0.24-4.07$ \\
\hline High & $8(87.5 \%)$ & $84(87 \%)$ & & & \\
\hline \multicolumn{6}{|l|}{ Economic Status } \\
\hline Low & $36(37.5 \%)$ & $16(17 \%)$ & 0.021 & 3.00 & $1.05-9.01$ \\
\hline High & $60(62.5 \%)$ & $80(83 \%)$ & & & \\
\hline \multicolumn{6}{|l|}{ Employment } \\
\hline Yes & $24(25 \%)$ & $32(33 \%)$ & 0.369 & 0.66 & $0.24-1.76$ \\
\hline No & $72(75 \%)$ & $64(67 \%)$ & & & \\
\hline
\end{tabular}

Regarding to Table 2, immunization status shows a significant relationship to the incidence of ARIs $(p=0.007)$. It can be inferred status incomplete immunization $3-5.7$ times greater in the group of ARIs compared to the group not ARIs. The analysis of economic status showed a significant relationship with the occurrence of ARIs $(p=0.02)$. It can be concluded the economic status of low risk, three times greater in the group compared to the group not ARIs. Mother's education and employment showed no significant relationship to the occurrence of ARIs.

Table 2. The results analysis of the external variables relations with early weaning

\begin{tabular}{|c|c|c|c|c|}
\hline \multirow{2}{*}{ Variables } & \multicolumn{2}{|c|}{ Early Weaning } & \multirow{2}{*}{$X^{2}$} & \multirow{2}{*}{$p$ Value } \\
\hline & Yes & No & & \\
\hline \multicolumn{5}{|l|}{ Nutrition Status } \\
\hline Poor & $34(27 \%)$ & $8(12 \%)$ & 3.15 & 0.076 \\
\hline Good & $90(73 \%)$ & $60(88 \%)$ & & \\
\hline \multicolumn{5}{|c|}{ Immunization status } \\
\hline Incomplete & $44(35 \%)$ & $12(18 \%)$ & 3.38 & 0.062 \\
\hline Complete & $80(65 \%)$ & $56(82 \%)$ & & \\
\hline \multicolumn{5}{|l|}{ Education } \\
\hline Low & $16(13 \%)$ & $8(12 \%)$ & 0.03 & 0.871 \\
\hline High & $108(87 \%)$ & $60(88 \%)$ & & \\
\hline \multicolumn{5}{|l|}{ Economic Status } \\
\hline Low & $36(29 \%)$ & $16(24 \%)$ & 0.34 & 0.561 \\
\hline High & $88(71 \%)$ & $52(76 \%)$ & & \\
\hline \multicolumn{5}{|l|}{ Employment } \\
\hline Yes & $44(35 \%)$ & $12(18 \%)$ & 3.38 & 0.065 \\
\hline No & $80(65 \%)$ & $56(82 \%)$ & & \\
\hline
\end{tabular}

\subsection{Multivariables Analysis}

Multivariable analysis was conducted to determine the effect of independent variables (early weaning) and dependent variable (ARIs) after the analysis together with external variables significant at bivariable analysis (immunization status, nutritional status and economic status). The statistical test used was logistic regression test by looking at the value OR CI 95\% and a significance level of $p<0.05$.

The value of the coefficient of determination $\left(\mathrm{R}^{2}\right)$ to see how much the independent variable can predict the dependent variable, the greater the value of $\mathrm{R} 2$, the better the independent variable to predict the dependent variable. 
Table 3. The Results of logist ic regression analysis of early weaning relationship with ARIs

\begin{tabular}{|c|c|c|}
\hline Variables & Odd Ratio (OR) & p Value $(95 \%$ CI) \\
\hline Early Weaning & & \\
\hline Yes & 2.72 & $1.08-6.83$ \\
\hline $\begin{array}{l}\text { Immunization status } \\
\text { Incomplete } \\
\text { Complete }\end{array}$ & 1.46 & $0.39-5.45$ \\
\hline $\begin{array}{l}\text { Nutrition Status } \\
\text { Malnutrition } \\
\text { Good nutrition }\end{array}$ & 2.28 & $0.55-9.49$ \\
\hline $\begin{array}{l}\text { Ekonomic Status } \\
\text { Low } \\
\text { High }\end{array}$ & 2.06 & $0.67-6.36$ \\
\hline $\mathrm{R}^{2}$ & & $\begin{array}{l}0.11 \\
192\end{array}$ \\
\hline
\end{tabular}

Table 3 shows that immunization status, nutritional status and economic status is not statistically significant. In the analysis found a significant association between early weaning with ARIs, and it can be concluded early weaning risk 2.72 times greater in the group compared are not ARIs $(\mathrm{OR}=2.72 ; 95 \% \mathrm{CI}=$ 1.08 - 6.83) and of $\mathrm{R}^{2}$ show the variables examined in this study can predict the incidence of ARIs $11.4 \%$ indicated with $\mathrm{R}^{2}=0.114 .88 .6 \%$ there are other factors that cause ARIs in children were not studied.

This study early weaning had a significant relationship with the occurrence of ARIs in children, as well as variable nutritional status, immunization status and economic status has a significant relationship with the occurrence of ARIs, it shows the impact of weaning early against harmful intake of nutrients and protective children, one of which is the content of $\operatorname{SIgA}(\operatorname{IgA})$.

Children aged 6 - 23 months at a risk of respiratory infection [20]. In children who are at risk of early weaning of 3.27 times more likely to suffer ARIs [1] and babies who were hospitalized 4.9 times more in infants who are not breast-fed and risk 2.45 times greater in infants who received breast milk $<4$ months [21]. A study of 170 subjects reported that the breastfed baby is not full and the given formula has a risk of ARIs [9]. Times more likely to suffer ARIs compared to infants who were exclusively breastfed for 4 months [12]. Babies who are breastfed partial have 2.23 times higher risk of suffering from ARIs and diarrhea compared with exclusive breastfeeding [7].

Factors related to mothers with premature weaning on the grounds of working mothers, breastfeeding is not enough and low socioeconomic level. A study of 923 subjects reported factors that lead to premature weaning conditions include low economic status, perception of parents that the baby was hungry, and cultural feeding grounds babies [12]. Mother did early weaning among other things because the mother is sick so the milk is broken, the mother of taking drugs and lack of knowledge of mothers about breastfeeding [22].

Analysis on nutritional status in this study showed a significant relationship between nutritional status and the incidence of respiratory infections, malnutrition status and opportunities 4.3 times greater in the group compared to no ARIs. Research in Bangladesh reported their nutritional status is a significant relationship with ARIs, while children with malnutrition 1.7 times greater risk of suffering from ARIs (95\% CI 1.1 - 2.5). Nutrition is enough to protect against infection because the immune system will function properly and nutritional status is important to prevent the occurrence of respiratory infections, adequate nutrition will protect the body from infection because the immune system will function properly [18],[23].

Analysis on the immunization status in the present study found a significant relationship with ARIs immunization status, and opportunities among respondents with incomplete immunization status was 3.57 times greater $(95 \% \mathrm{CI} ; 1.26$ to 10.64$)$ in the group compared to the not ARIs. Immunizations are many related to the incidence of ARIs is DPT and measles. In fact, the field of immunization is often incomplete, DPT often incomplete due to the effects of fever after immunization which makes the mother did not bring back her baby, causing drop out, while for measles immunization is often over looked by parents due to the interval with the basic immunization others too far.

Taksande reported incomplete immunization of 2.17 times greater risk for the occurrence of ARIs (95\% CI 1:32 to 4:04), other researchers reported a significant relationship with ARIs immunization status for immunization aims to immunize against diseases that can be prevented by immunization and immunization is one way of preventing serious infectious disease that is the most effective cost [1],[6],[19],[24]. This study found no significant relationship with the mother's education ARI. This suggests that the respiratory disease caused by other factors, the success of health promotion programs, the development of gadgets, the extent of access to the internet so that the information on ARIs easily obtained by the public in that educated mothers and mothers with low education.

IJPHS Vol. 6, No. 2, June $2017: 118-125$ 
Parental education does not have a significant relationship to the occurrence of ARIs [25], different things reported by other researchers that mothers with low education was 2.57 times greater risk for an ARIs (95\% CI=1.47 - 4.34), other researchers reported that there was a significant relationship maternal education with a high incidence of ARIs [1],[19]. Educational facilitate mothers can receive and apply information about good parenting. Higher education will be more likely to accept something cognitive, and behavioral changes can be initiated in the presence of sufficient knowledge [1],[2].

Analysis of the economic status of the result a significant relationship with ARIs economic status, Chances of lower economic status three times greater (95\% CI; $1.05-9.01)$ in the group ARIs. Than not, so it can be concluded the risk of events ARIs is higher in mothers with low economic status compared with mothers considerable economic status. Besides high economic status are more likely to provide many nutritional needs so that children are met. The state of good nutritional status can also improve immune function, so avoid the disease. The results of this study together in a case control study found a significant correlation with the economic status [1],[2].

Analysis of the jobs obtained no significant relationship with the mother's occupation ARIs. In significant risk of work on this research possible because the difference in a relatively small proportion. Besides, the proportion of ARIs most of it occurs in women who do not work, while the possibility of working mothers still pay attention to their children after work so that their condition can disturb the health of her mother's quick response. This shows that the occurrence of ARIs can be caused by other factors. The results of this study together that working mothers do not significantly associated with the incidence of ARIs in children [20],[26].

Nutritional status showed no significant association with ARIs in children, but in practice it can be seen that children with malnutrition status at greater risk to get respiratory diseases. The authors report a significant correlation anatara nutritional status and the incidence of ARIs in infants, while other researchers reported that the nutritional status was not statistically significant on the incidence of respiratory infections, malnutrition and normal nutritional no different risks against cough and cold, except in a state of chronic malnutrition.

Nutritional status in this study is not significant because the comparison is malnutrition status with good nutritional status, which in children with malnutrition status, the system of immunity still works well and the local immunity has not happened mucosal atrophy cilia respiratory tract except in children with nutritional disorders heavy. Results of multivariable analysis showed that the immunization status indicates that the relationship is not statistically significant with ARIs, but practically incomplete immunization status indicates a greater risk for the occurrence of ARIs in children. This occurs because of the success of immunization programs that can reduce the incidence of ARIs in Puskesmas Sukaraya OKU District, the achievement of the basic immunization of more than $90 \%$.

Results of multivariable analysis on economic status showed that the relationship was not statistically significant with ARI, but practically low economic status 2.3 times greater risk for the occurrence of ARIs. The study by the same design reported a significant correlation with the economic status of ARIs in infants [1],[19]. The difference these results partly because the study was conducted in urban areas while the Savitha and Taksandee research conducted in rural areas.

Early weaning relationship with ARIs in children does not occur because of chance alone but there is a causal relationship as evidenced by the confidence interval does not include zero. The results of logistic regression analysis in this study were found early weaning of 2.72 times greater risk for the occurrence of ARIs $(95 \% \mathrm{CI}=1.08-6.83)$. Early weaning or breast-fed infants are partial to 3.27 times greater risk of occurrence of ARIs (95\% CI 3.27- 5.76) Babies who are not breastfed or breastfed partially filled with susceptible to respiratory diseases and diarrhea [1],[7]. Risk infants who are not breastfed get a full or partial breastfeeding on the incidence of death from respiratory diseases and diarrhea at 2.23 times higher compared with exclusive breastfeeding. Infants admitted to the hospital 4.9 times higher in infants who are not breastfed, and 2.45 times higher in infants who are breastfed < 4 months [21]. Children ages 6 months to 23 months and do not get full and not getting good care at home are most at risk for the occurrence of ARIs [1],[7],[20].

Breastfeeding is known to have unique substance is an anti-infective. Breast milk also provides passive protection for the child's body to face the pathogens that enter the body. Especially exclusive breastfeeding in the first months of a baby's life can reduce the incidence and severity of infectious diseases [27]. In this study, early weaning had a significant relationship with the incidence of respiratory infections; need to intervene handling of children suffering from ARIs, not only through curative efforts but also through promotive. ARIs to reduce morbidity in children needs to be done prevention or risk factors through cooperation across programs and sectors, such as through cooperation with immunization programs, infant health development program, development program community nutrition and sanitation program.

In raising efforts and measures the dissemination of information for the prevention and control of respiratory diseases, all health care workers should have competence in delivering materials to the strategy of 
prevention and suppression of respiratory diseases, Nursing Academic of Baturaja as an educational institution can also be a front axle in giving health education especially about the importance of exclusive breastfeeding and the impact of early weaning.

As for the steps that can be taken in the form improve information, education and communication (IEC) to conduct training for health workers/ health workers on the management of breastfeeding, exclusive breastfeeding, and of ARIs in order to decrease the morbidity and mortality in children caused by ARIs. Another thing also can be done through increased cooperation across programs and across sectors in the prevention of respiratory disease in children.

For the implementation of the agreement may need to charge the integrated counseling and training for related sectors. Fostering public participation to monitor expectant mothers and breastfeeding whether breastfeeding has been implemented in an effort to decrease the incidence of weaning early in society, collaboration with women's organizations who care about the health problems of mothers and children, health volunteers and across relevant sectors to provide guidance and motivation pregnant and lactating mothers.

Activities that can be done in the form of health education about the importance of exclusive breastfeeding for the first 6 months of a baby's life and then keep breastfeeding until the age of 2 years with supplementary feeding for correct and educate mothers about the dangers when done weaning early so expected later can reduce the incidence of ARIs in children. Results of multivariable analysis illustrates that the economic status are less practical meaning to the ARIs in children. Interventions that can be given to people not in the form of finance, but in the form of promotional activities to improve health as well as nutritional status, which in this study found malnutrition status is practically meaningless to ARIs.

Nursing Department of Baturaja is educational institutions through community service activities in promotive, preventive while curative action can be coordinated with the health care institution in this case Pukesmas Sukaraya against efforts to reduce morbidity and mortality caused by ARIs. Problems affecting ARIs can not be resolved to its conclusion when the risk factor of ARIs not found spesifik.

The risk factors that increase the incidence of ARIs, especially pneumonia are: age less than 2 months, male, malnutrition, low birth weight, not breastfeeding are adequate, air pollution, overcrowding of residence. Other risks are also immunization is inadequate, vitamin A deficiency, giving the food was too early and ventilation inadequate housing, and children aged 6-23 months at the most at risk of ARIs [9],[20].

\section{CONCLUSION}

Early weaning is at greater risk of ARIs in children aged 6-24 months with an average ARI episode of 2.8 times every year. To decrease the incidence of early weaning, it needs proactive activity by health workers especially midwife and lactation management training needs to be done to improve mother skill in giving exclusive breastfeeding. The variables studied in this study were able to predict the incidence of ARIs by 11 percent; therefore it is necessary to do further research that is more specific to the special efforts to increase the immunological substances in breast milk that can prevent the occurrence of ARIs.

\section{ACKNOWLEDGEMENTS}

The authors are gratefull to midwife on facilitation and willingness to help during the data collection process as well as respondents who have collaborated in this research smoothness.

\section{REFERENCES}

[1] A. M. Taksande and Yeole M., "Risk factors of acute respiratory infection (ARI) in under fives in a rural hospital of Central India," J Pediatr Neonat Individualized Med, vol/issue: 5(1), pp. 1-6, 2015.

[2] M. Cooke, et al., "A description of the relationship between breastfeeding experiences, breastfeeding satisfaction, and weaning in the first 3 months after birth," J Hum Lact., vol/issue: 19(2), pp. 145-156, 2003.

[3] Abdel K. E. M., et al., Acute respiratory tract infections in children under 5 years of age in Upper Egypt," Int J Community Med Public Health, vol/issue: 3(5), pp. 1161-1166, 2016.

[4] B. W. William, et al., "Estimates of world-wide distribution of child deaths from acute respiratory infections," Lancet Infect Dis, vol/issue: 2(1), pp. 25-32, 2002.

[5] L. A. Hanson, "Breast-feeding and protection against infection," Scan J Nutr, vol. 50, pp. 32-34, 2006.

[6] W. E. Nelson, et al., "Child Health," Translation Wahab, A.S., Jakarta, EGC, 2000.

[7] S. Arifeen, et al., "Exlusive breastfeeding reduce acute respiratory infection and diarrhea deaths among infants in Dhaka slums," Pediatrics, vol/issue: 108(4), pp. E67, 2001.

[8] W. H. Oddy, et al., "Breast feeding and respiratory morbidity in infancy: a birth cohort study," J Arch.Dis.Child, vol. 88 , pp. 224-228, 2013. 
[9] Ministry of Health Republic of Indonesia, "Guidelines for the Pneumonia Management of Children Under Five Years," Jakarta, 2007.

[10] M. Haku, "Breastfeeding: factor associated with the continuation of breastfeeding, the current situation in japan, and recommendation for further research," J Med Invest., vol. 54, pp. 224-234, 2007.

[11] A. Al-Shoshan, "Factor affecting mother's choice and decisions related to breast feeding practices and weaning habits," Pak J Nutr, vol/issue: 6(4), pp. 318-322, 2007.

[12] C. M. Wright, et al., "Why are babies weaned early? Data from a prospective population based cohort study," Arch Dis Child, vol/issue: 89(9), pp. 813-816, 2004.

[13] M. Cooke, et al., "A description of the relationship between breastfeeding experiences, breastfeeding satisfaction, and weaning in the first 3 months after birth," J HumLact., vol/issue: 19(2), pp. 145-156, 2003.

[14] M. S. Kramer, et al., "Pacifier use early weaning and cryfuss behavior: a randomized controlled trial," JAMA, vol/issue: 286(3), pp. 322-326, 2001.

[15] M. L. Alarcon, et al., "Breast-fedding lowers the frequency and duration of acute respiratory infections and diarrhea in infants under six months of age," J Nutr, vol/issue: 127(3), pp. 436-443, 1997.

[16] R. Fauzie, et al., "Pattern and influencing factor of breastfeeding of working mothers in several areas in Jakarta," Paediatr Indonesia, vol/issue: 47(1), 2007.

[17] A. Koch, et al., "Risk factors for acute respiratory tract infections in young Greenlandic children," Am J Epidemiol, vol/issue: 158(4), pp. 374-384, 2013.

[18] Z. Fatmi and F. White, "A comparison of "cough and cold" and pneumonia: risk factors for pneumonia in children under 5 years revisited," Int J Infect Dis, vol. 6, pp. 294-301, 2002.

[19] M. R. Savitha, et al., "Modifiable risk factors for acute lower respiratory tract infections," Ind J Ped, vol/issue: 74(5), pp. 447-482, 2007.

[20] Yousef F. M. and Hamed A. F., "Prevalence of acute respiratory infection and related risk factors in school age children in Egypt: a cross-sectional study," Int.J.Curr.Res.Med.Sci, vol/issue: 2(7), pp. 50-58, 2016.

[21] J. M. P. Talayero, et al., "Full breastfeeding and hospitalization as a result of infection in the first year of life," Pediatrics, vol/issue: 118(1), pp. e92-e99, 2006.

[22] O. D. Araujo, et al., "Breastfeeding; Factors That Cause Early Weaning," Rev Bras Enferm, vol/issue: 61(4), pp. 488-492, 2008.

[23] N. Etiler, et al., "Incidence of acute respiratory infectious and the relationship with some factors in infancy in Antalya, Turkey," Pediatr Int, vol/issue: 44(1), pp. 64-69, 2002.

[24] K. A. Neighbors, et al., "Weaning Practice among breastfeeding woman who weaned prior to six months postpartum," J Hum Lact, vol. 19, pp. 374, 2003.

[25] C. J. C. Chantry, et al., "Full breastfeeding duration and associated decrease in respiratory tract infection in US children," Pediatrics, vol/issue: 117(2), pp. 425-432, 2006.

[26] Geberetetsadik A., et al., "Factors associated with acute respiratory infection in children under the age of 5 years: evidence from the 2011 Ethiopia Demographicc and Health Survey," Pedeatric Health, Medicine and Therapeutics, vol. 6, pp. 9-13, 2015.

[27] N. M. Marques, et al., "Breastfeeding and early weaning practices in Northeast Brazil: a longitudinal study," Pediatric, vol. 66, pp. 108, 2001. 